\title{
Integration Processes In Russia Engineering: Condition For Business Continuity
}

\author{
Ekaterina Strizhakova ${ }^{1}$, Dmitry Strizhakov ${ }^{1}$ and Igor Simontsev ${ }^{1}$ \\ ${ }^{1}$ Bryansk State Technical University, 241035 Bryansk, 7a bulvar 50-letiya Oktyabrya, the Russian \\ Federation
}

\begin{abstract}
Annotation. The article discusses the nature and main approaches to the integration of enterprises and organizations of mechanical engineering, introduces the concepts of «business continuity» and «business continuity management», offers recommendations for the implementation of a business continuity management procedure in mechanical engineering enterprises. According to the authors, integration refers to the process of strengthening production relations and economic relations, the organizational and economic merging of several components (components, parts) into a single whole, acquiring a higher quality than the arithmetic addition of parts. The limits of the integration processes of the organization are analyzed according to the three possible modern concepts of the company. The evolution and main stages of the integration processes in the engineering industry of Russia for the period from 1991 to the present are analyzed in the article. The current state of the level of integration in the engineering industry of Russia is also given. The assumption about the direct correlation between business continuity and the degree of integration in the engineering industry of Russia is formulated. The prospects for the further development of the integration of industrial enterprises in Russia are evaluated.
\end{abstract}

\section{Introduction}

According to the GOST R 53647.1-2009 «Business Continuity Management. Part 1. Practical Guide» business continuity means the «strategic and tactical ability of an organization to plan its work to ensure business continuity». This standard also specifies the concept of business continuity management (HSR) as «a management process that includes identifying and analyzing potential threats, developing and implementing response measures to protect the interests of a company».

For the implementation of business continuity management in an organization, it is recommended to include such procedures as: analysis and identification of key business processes, identification, assessment and risk analysis, formation of a company's business continuity management strategy, preparation and approval of a business continuity plan, initial testing of plans, staff training and education, monitoring and feedback. 
It should be taken into account that this procedures for the implementation of business continuity management require substantial material and financial costs, as well as the availability of trained qualified personnel. Therefore, only large integrated structures have the opportunity to take advantages of business continuity management. Thus, these structures significantly increase their competitiveness, minimize costs, increase profits and the efficiency of the activity as a whole.

There are two main types of integration of enterprises - vertical and horizontal.

Vertical integration is a consolidation of enterprises located in in the direction of the technological process, thus, there is an association of enterprises, one or several of which were the suppliers of raw materials or semi-finished products for a number of others [1].

Vertical integration can be done in two main directions:

a) reverse vertical integration, or consolidation with suppliers or subsidiary structures that provide supply. Machine-building enterprises receive significant advantages by reducing the prices of semi-finished products and components, as well as reducing the risk of their change.

b) direct vertical integration, or consolidation with distributing and selling enterprises. Machine-building enterprises use this type of integration if there is no adequate intermediaries to work with end-users.

In some economic literature it is indicated that the third direction is also possible [2-6]: a complex direction, as a result of which the subsequent and previous stages of production are included around a single mainstay technology.

Horizontal integration is typical for the combination of economic structures that produce homogeneous products and provide the same services [7]. Horizontal integration of machine-building enterprises is the consolidation of business through the merger of similar plants and enterprises or enterprises that perform identical operations of the technological cycle.

\section{Methods}

The advantages and disadvantages of integrating machine-building enterprises should be considered similarly to the main concepts used by firms - technological, institutional, and strategic [8-11].

According to the technological concept, the enterprise will independently produce products if the costs for production within the enterprise are lower than the costs for buying from others organizations. If the vertical or horizontal integration leads to a reduction in the costs, then this option of interaction will be a priority. Thus, the main indicator that determines the expediency of further expansion of the enterprise is the value of subadditive costs or costs, the value of which decreases when organizations are combined. In this case, the minimum effective size of a firm depends on the magnitude of demand existing in the market, and the maximum size depends on the moment until which the subadditive costs are reduced. The limit, after which the subadditive costs cease to decrease with increasing firm size, is called the technological frontier of the firm.

The second concept of the company is institutional concept. In this theory according to R. Kouz, the boundaries of the firm are depending on the transaction costs that limit the growth of the firm from below, and on the internal costs of control affecting growth from above. J.K. Galbraith, who treats a developed corporation as the main source for replacing the market with planning, sees in the growth of the company's scale positive moments both for the company itself and for industry and for society as a whole. The integration of industrial enterprises will reduce the amount of risk. 
According to F. Perru and G. Myrdal, integrated enterprises have a positive impact on the entire economy of the country, due to the "curvature of space», the movement of resources to the enterprise and the synergistic effect.

O. Williamson points out that the integrated enterprises reduce the duration of negotiations, transaction costs and non-production costs.

The strategic concept of the firm departs from the idea of the firm as a slave subject of economic relations, which obeys to changing environmental conditions. Within this concept, an enterprise is using its own active strategy, i.e. development strategies involving technological innovation, has the ability to influence the environment. It should be noted that the strategy of technological leadership is practically impossible for small firms, since the costs and magnitude of the risk in implementing this strategy are critical for enterprises of this size. So only vertically integrated engineering enterprises remain competitive in this situation.

Thus, the presented concept of the company focuses on three main areas that benefit from integration: saving resources and reducing costs, reducing transaction costs and eliminating incomplete contracts, as well as expanding the capabilities of the enterprise to implement innovation.

\section{Results \& Discussion}

There is no doubt that vertically and horizontally integrated companies also have sufficient resources to implement strategies associated with significant R \& D expenditures, and also due to the significant differentiation of their products they have the ability to compensate for likely unsuccessful innovation projects.

The integration process in the Russian machine-building complex is usually divided into the following four stages.

The first stage: 1991 - 1996. The transition of the country's economy to the market basis led to the high activity of financial corporations and banks, their purchase of industrial enterprises belonging to various industries. Often the association of enterprises occurs only for the redistribution and subsequent resale of assets for profit.

The second stage: 1996-2000. The formation of holding structures, the creation of vertically integrated machine-building enterprises aimed at making a profit from production activities happens at this stage.

The third stage: 2000 - 2014. Industrial enterprises understand the benefits of integration, the processes of consolidation enterprises intensifies, and the state support is increasing, especially for enterprises belonging to the defense-industrial complex. Creation of vertically integrated structures in industry - corporations, concerns and holdings takes place.

Fourth stage: 2014 - present. The introduction of sanctions has led to the integration of machine-building enterprises belonging to different sub-sectors, as well as producing dualuse products.

Let us analyze the enterprises of the machine-building complex, which are in the rating of the largest 400 enterprises in Russia, according to the research of the analytical center «Expert». The engineering industry is the fourth largest aggregate revenue of the largest enterprises: of the 400 companies represented in the rating, 38 corporations belong to this type of activity with a total revenue of 5.3 trillion rubles. It should be noted that all of them represent holdings, corporations such are, therefore, are integrated structures. If you rank the enterprises by the size of the employed, the analyzed sector will be in second place after the oil and gas industry. A distinctive feature of the sector is the high share of the state $58 \%$, and also of foreign firms $-20.2 \%$. 
According to the research, labor productivity in machine building is very low, at 3.5 million rubles per person per year, but a positive trend is its rapid growth, in 2017 it was $11.5 \%$.

The integration of machine-building enterprises is partly a necessary measure, since international sanctions, the loss of partners geographically located in Ukraine, the United States, the European Union significantly increase the risks of doing business and the likelihood of production stoppage. In turn, integrated structures are easier to adapt to external influences, while some of the risks that were previously determined by the external environment go into the category of manageable internal risks (for example, by integrating with suppliers of raw materials and components, uncertainty in supplies is eliminated) [12 $16]$.

\section{Conclusion}

Integration allows you to create certain reserves for the conduct of activities related to ensuring business continuity and the implementation (if necessary) of a number of anticrisis measures. The survival rate and success of a large integrated structure is much higher than in the conditions of other forms of business, it is evidenced by statistical data and numerous empirical studies. Providing reserves for the survival of firms and businesses ensures predictability of budget revenues and defense capability. Thus, it is necessary to integrate industrial and financial capital in mechanical engineering, subordinating the internal capital formation process and the internal investment process to create large series for the production and internal and external consumption of industrial products. This will allow enterprises to produce competitive products that are in steady demand and increase their efficiency.

\section{References}

1. E. Strizhakova, IOP Conference Series: Materials Science and Engineering Cep. "International Conference on Mechanical Engineering, Automation and Control Systems 2015", 124, 012097 (2016)

2. U. Fazlollahi, International Journal of Production Economics, 200, 119 (2018)

3. M. Mahmoodpour, A. Lobov, Procedia Manufacturing, 31, 283 (2019)

4. S. Khurana, A.Haleem, B.Mannan, Journal of Cleaner Production, 229, 374 (2019)

5. Y. Gong, M. Janssen, International Journal of Information Management, 46, 1 (2019)

6. K. Ibeh, D. Makhmadshoev Journal of Business Research, 93, 255 (2018)

7. M.K.Shad, F.-W. Lai, C.L.Fatt, J.J.Klemeš, A.Bokhari, Journal of Cleaner Production, 208, 415 (2019)

8. D. Ortiz-Avram, J. Domnanovich, C. Kronenberg, M. Scholz, Journal of Cleaner Production, 201, 254 (2018)

9. B. Szijarto, P.Milley, K.Svensson, J. B. Cousins, Evaluation and Program Planning, 66, 20 (2018)

10. J. Cheah, A.Amran, S.Yahya, Journal of Cleaner Production, 211, 607 (2019)

11. G. Shanks, M.Gloet, I. A. Someh, K. Frampton, T. The Journal of Strategic Information Systems, 27, 139 (2018)

12. V. Nocke, N.Schutz, Journal of Economic Theory, 169, 603 (2017) 
13. V. Nocke, P. Rey, Journal of Economic Theory, 177, 183 (2018)

14. T. Kikuchi, J.Stachurski, G. Vachadze, Journal of Economic Theory, 176, 170 (2018)

15. G.-M. Angeletos, V. Panousi, Journal of Economic Theory, 146, 863 (2011)

16. S.-K. Peng, J.-F. Thisse, P.Wang, Journal of Economic Theory, 131, 1 (2006)

17. F. J. Buera, J. P. Kaboski, Journal of Economic Theory, 147, 684 (2012) 